\title{
O USO DOS PROCEDIMENTOS DE AUDITORIA COMO FERRAMENTA PARA IDENTIFICAR FRAUDES E ERROS NAS EMPRESAS DO RAMO DE MATERIAIS DE CONSTRUÇÃO CIVIL NO MUNICIPIO DE NOVA OLÍMPIA
}

\author{
Israel P S Filho ${ }^{1}$ \\ Marcelo Evandro Alves ${ }^{2}$
}

\section{RESUMO}

Geralmente as empresas de pequeno porte são administradas pelos próprios sócios, que muitas vezes tem formação técnica ligada ao seu negócio, e cada vez mais necessitam de informações e controle precisos para tomada de decisões. Devem sempre observar as atualizações e lidar com novas operações, a auditoria para avaliar o sistema de controle de estoque tem que ser sempre planejado. $\mathrm{O}$ presente artigo tem por finalidade avaliar o uso correto das ferramentas da auditoria de estoque como ferramenta para identificar fraudes e erros que possam surgir nas empresas do ramo de materiais de construção no Município de Nova Olímpia. Justifica-se o presente estudo, pelo fato das empresas buscarem gerar maior competitividade no seu negocio, ações que permitam diferenciá-las de seus concorrentes e venham a reduzir custos. $\mathrm{O}$ principal problema está voltado para o baixo grau de exatidão, ou seja, as quantidades físicas são divergentes das registradas no sistema de controle de estoque e se empresas utilizam esses procedimentos corretamente. A metodologia aplicada no estudo foi bibliográfica, qualitativa e exploratória, voltada principalmente para o setor de gestão de estoque das empresas. $\mathrm{O}$ resultado atingido foi satisfatório quanto ao problema proposto, demonstrando fatores positivos como a prevenção de falhas, erros e fraudes.

Palavras - chaves: Auditoria. Controle de estoque. Gestão de estoques.

\section{INTRODUÇÃO}

A auditoria exerce uma ação preventiva, saneadora e moralizadora, para confirmar a veracidade dos registros e a confiabilidade dos comprovantes, com o fim de opinar sobre a adequação das situações contidas nas demonstrações contábeis, na salvaguarda dos direitos dos proprietários, dos financiadores do patrimônio, do próprio "físico" e até, da sociedade em geral (FRANCO; MARRA, 2001).

A auditoria destaca-se como disciplina que se empenha em identificar falhas, fraudes e erros nos processos de movimentação e armazenagem de mercadorias, verifica os registros contábeis corrigindo possíveis erros, trazendo para o empreendedor segurança e confiabilidade nos registros. Em linhas gerais, definem-se como principais objetivos da auditoria de estoque os seguintes itens: verificar se as quantidades de bens declarados realmente existem; verificar se os bens foram custeados e avaliados de acordo com os

\footnotetext{
${ }^{1}$ Acadêmico do curso de Ciências Contábeis da UNEMAT - Campus de Tangará da Serra, israel_lanatico@hotmail.com

${ }^{2}$ Professor do Departamento de Ciências da UNEMAT - Campus de Tangará da Serra, marcelo.evandro@unemat.br
}

Revista UNEMAT de Contabilidade, ano 1, n.1, jan./jun. 2012. 
princípios de contabilidade geralmente aceitos e a consistência dos procedimentos em relação ao ano anterior (ALMEIDA, 2003).

Sabendo que a auditoria é uma eficiente ferramenta na identificação das fraudes e erros dentro das organizações, surge a possibilidade de utilizar seus procedimentos em beneficio da gestão de estoque, é com base neste argumento define-se a necessidade de diagnosticar um problema: as empresas utilizam corretamente os procedimentos de auditoria em estoque como ferramenta na identificação de fraudes e erros?

O objetivo consiste em uma indicação da ação ampla do problema, por isso mesmo ele deve ser elaborado com base na pergunta de pesquisa. Essa ação ampla costuma ser de difícil execução e avaliação se não ocorrer sua tradução em objetivos específicos (BEUREN, 2003). Já Ribeiro (2006, p. 18) diz que: "deve conter de forma simples, objetiva e direta qual a pretensão do trabalho, o que se pretende construir com o estudo. Está ligado a uma visão global e abrangente do tema do trabalho pressuposto".

O Objetivo geral deste artigo é demonstrar através dos resultados obtidos com questionários se o uso correto dos procedimentos da auditoria nos estoques dentro das organizações é efetuado de maneira correta e coerente com a auditoria. Como objetivo específico, busca destacar em quais pontos possam existir falhas no controle de estoques das empresas. A mesma justifica-se a fim de apoiar as empresas no uso freqüente da auditoria como ferramenta para identificar e prevenir possíveis fraudes e erros em seus estoques, e o baixo grau de exatidão, ou seja, as quantidades físicas são diferentes nas registradas no sistema. Beuren (2003, p.78) “ menciona que o autor deve justificar seu estudo, apontando-lhe contribuições de ordem prática e ao estado da arte na área em que está buscando formação acadêmica."

A auditoria em estoque já foi mencionada como objeto de estudo em outros artigos acadêmicos conforme tratam em suas pesquisas, Gelatti et al (2007) que partilham da mesma idéia quando relatam sobre a importância da auditoria nos estoques. É baseado nestes estudos que esta pesquisa foi elaborada, porém com enfoque para o ramo de materiais de construção. O objeto de trabalho da auditoria consiste no exame do conjunto de todos os elementos de controle do patrimônio, os quais compreendem os registros contábeis, papéis, documentos, fichas, arquivos e anotações que comprovem a veracidade dos registros e legitimidade dos atos e fatos administrativos. 


\section{FUNDAMENTAÇÃO TEÓRICA}

\subsection{Conceitos de Auditoria}

Auditoria é uma técnica aplicada ao sistemático exame dos registros, demonstrações e de quaisquer informes ou elementos de consideração contábil, visando apresentar opiniões, conclusões, críticas e orientações sobre situações ou fenômenos patrimoniais da riqueza aziendal, pública ou privada, quer ocorridos, quer por ocorrer prospectos e diagnosticados (SÁ, 2000). Através da auditoria são analisados e examinados os registros contábeis e documentos da entidade sobre os quais são emitidos parecer expressando se as demonstrações financeiras representam ou não, a situação real do patrimônio, seja tanto econômico como financeiramente, observando o princípio da competência.

A auditoria como ferramenta para identificar possíveis falhas busca interpretar, prever fatos, examinar, e como consequiência das suas interpretações criticarem, pois a auditoria não se limita apenas em verificar os fatos passados, ou seja, seu conceito é mais dinâmico, atribuindo-lhes importantes funções diretamente ligadas ao organismo da empresa, sendo sistemático, racional e técnico (SÁ, 2000). A auditoria está subordinada às suas normas e procedimentos, aos postulados da contabilidade e comportamentos éticos.

Uma auditoria de avaliação serve de assessoramento a alta gestão da empresa, que visa a avaliação dos sistemas de controle envolvidos e verificação dos procedimentos e das normas alocados no desenvolvimento do negócio exercido, sempre atentos para o desempenho operacional e para a eficácia obtida por suas áreas produtivas, levando em consideração todos planos de metas, objetivos e políticas definidas pela organização (SÁ, 2000).

\subsection{Planejamentos, Organização e Controle}

A princípio toda empresa deve planejar e definir suas atividades e as maneiras de como será feito o controle interno e organizar-se. Certamente a auditoria dos estoques merece essas atenções, uma vez que ligada as atividades da empresa tem impacto direto no resultado. Planejamento é o processo administrativo que determina antecipadamente as metas que deverão ser atingidas, para produção de relatórios, atendendo plenamente os usuários, 
sabendo do conhecimento contábil os usuários constroem com enfoque diversos relatórios gerenciais (SILVA; PADOVEZE, 2006).

O Sistema de informação contábil deve produzir informações que possam atender aos aspectos empresariais, ciclos administrativos e de estruturação da informação, o planejamento deve estar focado a todos os setores especulando as diversas maneiras e possibilidades que possam trazer pontos positivos para empresa tanto na formação de estoque quanto no gerenciamento (GIL, 1992).

Entende-se que planejamento administrativo significa decidir adiantadamente o que deve ser feito para alcançar determinado objetivo. Em aspectos históricos o estoque deve ser previsto antes do inicio das atividades da empresa, e temporariamente auditado, sendo planejado observando os métodos utilizados, que além de planejar os administradores organizam, dirigem e controlam as atividades da empresa.

Oliveira (1990, p.48) menciona que "se as informações gerenciais não forem utilizadas periodicamente, poderá ficar numa situação de descrédito perante seus usuários”, ou seja, toda empresa deve cuidadosamente planejar suas decisões para que haja controle, quanto ao planejamento do estoque, deve-se observar o impacto que esses causam na empresa.

Como os estoques constituem parcela considerável dos ativos da empresa, eles recebem um tratamento contábil minucioso. De maneira resumida o estoque é a parcela de atividade da empresa mais importante no ponto de vista de disponibilidades em curto prazo (SILVA; PADOVEZE, 2006). Esse tratamento causa impacto no processo de atividades da empresa, devem assim ser organizado de forma clara e objetiva, estima-se que a estrutura organizacional no processo administrativo da empresa possa atingir as metas propostas pelos sócios, administradores.

Segundo Silva, (1990, p. 36) “Organização é o processo administrativo que visa à estruturação da empresa reunindo pessoas e os equipamentos, de acordo com o planejamento efetuado." Cabe ao administrador organizar a empresa, dando-lhe determinada estrutura, que possa facilitar seu entendimento e direção, diretamente ligado a renovação de seus ativos, estoque, matérias prima.

O fundamento de administrar uma empresa está diretamente ligado a importância de controle, pois cabe ao administrador cumprir a tarefa de planejar, organizar, dirigir e controlar as atividades da empresa definindo suas metas e objetivos, logo a atenção deve voltar-se para o conceito do controle. Controle é o processo administrativo que consiste em verificar se tudo 
está sendo feito de acordo com o que foi planejado e as ordens dadas, bem como assinalar as faltas e os erros, a fim de repará-las e evitar sua repetição, na proporção em que as atividades estão sendo executadas (SILVA, 1990).

\subsection{A IMPORTÂNCIA DO CONTROLE DE ESTOQUE}

O estoque representa o custo das mercadorias possuídas por uma empresa numa data especifica, assumindo uma grande importância no contexto do Balanço Patrimonial (BP) e seus efeitos são imediatamente sentidos no Patrimônio Liquido, nesse estudo de estoque refere-se principalmente às empresas comerciais (OLIVEIRA; MARION; 1990, 2003).

Um dos itens mais importantes do Ativo de uma empresa comercial é o estoque, isto advém não só de sua participação no Ativo, e sim também do fato de ser a partir dele que se determina o custo das mercadorias ou produtos vendidos, afetando as despesas variáveis e conseqüentemente impactando no resultado do período.

Assim, determina-se uma conta que registra os bens adquiridos à serem revendidos ou transformados. Iudícibus (1986 p. 293) afirma que "o tipo de estoque que uma empresa possui, depende do seu objetivo social: se for uma empresa que comercializa produtos, ela compra e vende os mesmos produtos e seu estoque é constituído de mercadorias".

O básico é que os custos das mercadorias adquiridas devem compreender todos os gastos que a empresa realiza para adquiri-las e colocá-las em condições de serem vendidas. Para uma empresa que compra e vende mercadorias, tem custos incluídos no preço de compra e os gastos com transporte, recepção, inspeção e colocação nas prateleiras, além de custos administrativos associados ao controle dos estoques (LAUGENI; MARTINS; 2002).

Com a existência do custo das mercadorias e do valor de mercado, surge a necessidade de escolher o menor valor para avaliar o estoque. O problema para se chegar a essa conclusão e que depende do fato da empresa ter em estoque o mesmo produto adquirido com custos unitários diferentes. Se a empresa consegue identificar qual unidade foi vendida e quais unidades ficaram em estoque no final do período, a mensuração do custo das mercadorias vendidas e do estoque final não apresenta problemas. A semelhança física entre unidades de alguns produtos, entretanto, cria dificuldades para a identificação de quais unidades foram vendidas e quais ficaram em estoque (CAMPOS; MARTINS, 2000). 
Mesmo quando avanços na tecnologia permitem que a empresa acompanhe cada item de seu estoque, ela pode preferir não fazê-lo, dados os custos envolvidos, surge a dúvida sobre qual preço unitário deve ser atribuído ao estoque na data do balanço. O importante é que de acordo com os princípios contábeis do custo original como base de valor, deve se trabalhar com os valores de aquisição (entradas) das mercadorias, o que pode variar é o critério adotado para sua valoração (FAVARO, 1997; STECKNEY 2001).

\subsection{Estoques}

Estoques são bens ativos na forma de materiais ou suprimentos a serem consumidos no processo de produção, empregados na prestação de serviços, mantidos para revenda ou distribuição no curso normal das operações ou no processo de produção para venda (NBC, 2011). Entende-se por estoque, o acúmulo ou depósito de mercadoria ou matéria prima para produção ou posterior venda. Conforme Corrêa et al (2000; p.45) "estoques são acúmulos de recursos materiais entre fases específicas de processo de transformação".

A formação de estoque está relacionada ao desequilíbrio que existe entre a demanda e o fornecimento, por ser impossível prever rigorosamente a demanda dos clientes, faz-se necessário o estoque na empresa, sendo o meio que garante a disponibilidade da mercadoria exatamente no momento em que é requisitada, sendo assim, uma das principais funções da administração de materiais relaciona-se com o controle de níveis de estoque (BERTAGLIA, 2005; POZO, 2004).

Para isso faz-se necessário o rigoroso controle dos itens de estoque que vêm a ser registrado, a fim de evitar-se o constrangimento para empresa de ser requisitado determinado item e este não vir a existir no inventário da empresa, neste momento destaca-se a auditoria, que busca identificar essas faltas e corrigir determinados erros que possam ser identificados.

Toda empresa visa maximizar o lucro sobre o capital que venha a ser investido, seja em imobilizado, como também em financiamentos, reserva de caixa e estoques, espera-se então que todo dinheiro investido em estoques seja visto como a "energia" necessária para que a empresa tenha uma boa produção e um bom atendimento das vendas.

A Característica que os estoques representam nas empresas variam de acordo com suas atividades desenvolvidas, Gelatti et al (2007, p. 4) ilustram a classificação dos estoques como: Mercadoria para Revenda: Que é Composto por todos materiais adquiridos de terceiro 
destinados a revenda. Produtos acabados: Representam os produtos prontos produzidos na própria empresa e disponíveis para revenda. Produtos em Elaboração: Compostos pelos bens já requisitados que estão em processo de transformação e todos os custos diretos e indiretos relativos à produção ainda não concluída no encerramento do balanço. Matérias-Primas: Representadas pelos materiais que irão ser aplicadas na produção. Materiais Auxiliares: Composto por todos os itens destinados a embalagem ou acondicionamento dos produtos acabados. Importações em Andamentos: Engloba todos os itens de estoque já incorridos referentes a importação em andamento realizada pela empresa. Almoxarifado: Engloba todos os itens de estoques de consumo em geral, podendo incluir produtos de alimentação do pessoal, materiais de escritório, peças em geral e uma variedade de itens.

Muitas empresas, por questão de controle, adotam a prática de, para fins contábeis, já lançar tais estoques como despesas no momento da compra, somente mantendo controle quantitativo, pois muitas vezes representam uma quantidade muito grande de itens, mas de pequeno valor total, não afetando os resultados.

\subsection{Procedimentos de Auditoria de Estoques}

Os procedimentos da auditoria devem ser elaborados cuidadosamente para obter-se o máximo de proveito, a Resolução do Conselho Federal de Contabilidade n. ${ }^{\circ}$ 700/91 nos traz que "procedimentos de auditoria é o conjunto de técnicas que permitem ao auditor obter evidências ou provas suficientes e adequadas para fundamentar sua opinião sobre as Demonstrações Contábeis Auditadas, e abrangem teses de observância e testes substantivos".

Estes testes se objetivam a obter uma margem de segurança em conformidade com o pleno funcionamento dos procedimentos de controle interno executados, sendo evidentes, suficientes e que possam prever a validade das informações geradas pelo o sistema. Crepaldi (2004, p.23) aponta que a auditoria "consiste em controlar as áreas-chaves nas empresas a fim de evitar situações que propiciem fraudes, desfalques e subornos, através de testes regulares nos controles internos específicos de cada organização".

Lírio (2011) em sua tese publicada no portal da administração nos traz a importância da auditoria de estoque como proposta para redução de perdas e mensuração de resultados "a auditoria de estoques representa um elo fundamental entre o inventário e os resultados, externando de forma analítica os possíveis atores causadores da ineficiência”. 
O controle interno da empresa torna-se mais efetivo se submetido a freqüentes auditorias, estas de acordo com a Resolução CFC N ${ }^{\circ}$ 986/03, seguem os seguintes procedimentos: Inspeção - verificação de registros, documentos e ativos tangíveis; Observação - acompanhamento de processo ou procedimento quando de sua execução; Investigação e confirmação - obtenção de informações perante pessoas físicas ou jurídicas conhecedoras das transações e das operações, dentro ou fora da entidade.

Em todas as empresas qualquer procedimento de auditoria depende do controle interno praticado na mesma, do material disponível para se desenvolver a atividade de auditoria, e dos procedimentos praticados pelo perito, seja interno ou externo.

Os procedimentos mais utilizados pelos peritos durante a execução dos trabalhos de auditoria, (ATTIE, 1998), são: Exame físico - contagem de estoques de matérias-primas, em processo, acabados e materiais em consignação ou com terceiros. Confirmação - confirmação de estoques com terceiros; confirmação de estoques de terceiros; confirmação de estoques em consignação. Documentos originais - exame documental das notas fiscais por compra e pagamentos; exame de contratos de compra e venda; exame documental das apropriações de matérias-primas e mão-de-obra; exame de atas e assembléias. Cálculos - soma da contagem de estoques; cálculo das quantidades pelo preço unitário; cálculo dos impostos; apropriação das despesas gerais de fabricação. Escrituração - exame da conta razão de produtos acabados; exame da conta razão de importações em trânsito; exame das ordens de fabricação; Registros auxiliares - exame do registro perpétuo de estoques; exame das ordens de produção/fabricação.

Os procedimentos de auditoria nos estoques a serem adotados devem ser elaborados antes de sua aplicação, em acordo com a administração, sendo sempre com objetivo de ser direto e demonstrar resultados positivos, ele servirá de cronograma para o auditor ser flexível, baseado nele ele poderá se guiar, após seus procedimentos aplicados o auditor deverá tomar ações.

As principais ações sobre os programas de auditoria na área de estoques com objetivo de observação do inventario físico (FRANCO; MARRA, 2001), são: I - Revisar o planejamento da empresa para levantamento do inventário físico a fim de assegurar-se quanto à sua adequação. II - Efetuar reunião preliminar com os auxiliares e orientá-los devidamente quanto aos pontos mais importantes do inventário e as peculiaridades de trabalho. III - Obter a preparação do "corte" das entradas e saídas anotadas, em sincronização com o movimento dos 
materiais. IV - Obter ou preparar relações das notas fiscais de mercadorias faturadas e ainda não entregues. V - No decorrer do inventário físico, percorrer todos os grupos de inventariantes, fazer testes das contagens, conferindo-as de imediato com as anotadas pelo cliente e verificar se os procedimentos de cada grupo são corretos.

b) Programa de Auditoria de Estoques Complementar: Observância do Controle Interno, ações do auditor: I - Verificar através da verificação das rotinas se o controle interno nesta área está de acordo com o que foi descrito no questionário de controle interno. II Certificar-se de que o programa para observação do inventário físico foi devidamente respondido. III - Revisar os procedimentos da empresa para efetuar as contagens. IV - Efetuar a verificação do "corte" preparado por ocasião do inventário físico. V - Verificar se os itens testados durante o inventário físico encontram-se incluídos nas relações finais de inventários.

\subsection{Identificando erros e fraudes}

Durante a realização da auditoria, podem surgir alguns indícios ou fatos e que possam de que possa estar ocorrendo erros ou fraudes (SANTI, 1988), alguns deles são: Discrepâncias nos registros contábeis, exemplos: Diferenças na soma das contas analíticas comparadas ao saldo constante das contas sintéticas; Diferenças reveladas por confirmações recebidas de terceiros; Número de respostas aos pedidos de confirmação direta bem inferior ao esperado; Transações não suportadas por documentação apropriada; Transações não contabilizadas de acordo com instruções genéricas ou especificas da gerência; Transações inusitadas no fim ou próximo do fim do exercício. Depois de identificado algum erro ou fraude, cabe ao auditor comunicar aos órgãos responsáveis, que deverá observar e investigar se estes vêm ocorrendo com freqüência e quais os motivos que os levam a acontecer.

As Fraudes na maioria das vezes são praticadas por pessoas que possuem autoridades, no entanto quando acumulam funções. Quando implicam em números maiores, as fraudes geralmente ocorrem mediante formação de conluio, sendo assim, mais difícil a detecção. Portanto, nestes casos a fraude tende a persistir se não existir controles adequados e independência da auditoria (SÁ, 2000).

A Norma Brasileira de Contabilidade T11 define fraude como um ato intencional de omissão ou manipulação de transações, adulteração de demonstrações contábeis; e Erro é o ato não intencional resultante de omissão, desatenção ou má interpretação de fatos na elaboração de registros e demonstrações contábeis. Sá (2000, p.51) valoriza que "o auditor 
localiza, relata a correção dos erros, mas não é sua responsabilidade a execução da correção”. Os erros intencionais ou fraudes podem ser cometidos para: subtrair mercadorias, matériasprimas, produtos e resíduos; subtrair dinheiro, subtrair títulos, iludir o físco, evitando o pagamento de impostos, dissimularem atos sujeitos a penalidades, encobrir falta de terceiros, alterar resultados para usufruir maiores percentagens em lucros, simular ocorrências, iludir a opinião de acionistas e autoridades monetárias, etc.

\section{METODOLOGIA}

Segundo Ribeiro (2005, p. 21) "Método é o caminho a ser seguido a fim de que as metas sejam atingidas. Portanto a seleção do instrumental metodológico está diretamente relacionada com o problema a ser estudado". A metodologia utilizada foi exploratória, pois utilizou o estudo como pesquisa, buscando conhecer o assunto. Complementa que este tipo de pesquisa foi realizado especialmente quando o tema e pouco explorado tornando se difícil formular hipóteses precisas (GIL, 1992).

Quanto ao problema, a pesquisa foi qualitativa, porque foram feitas analises mais profundas em relação ao problema levantado (BEUREN, 2006). O conjunto de documentos utilizados para investigação com a finalidade de encontrar o caminho mais racional a fim de atingir os objetivos propostos, da melhor maneira. (BEUREN, 2006).

$\mathrm{Na}$ pesquisa foram utilizadas estudos bibliográficos extraídos de livros, através de leitura de artigos, pesquisa na internet e pesquisa de campo desenvolvida especificamente da área de auditoria e gerenciamento de estoque (RIBEIRO, 2006). Sua finalidade é colocar o pesquisador em contato direto com tudo o que foi escrito, dito ou filmado (MARCONI; LAKATOS, 1985). Foi aplicado questionário em 8 empresas do município de Nova OlímpiaMT, essencialmente no ramo de materiais de construção civil, no mês de Setembro do ano de 2011, onde os mesmos foram respondidos pelos proprietários. As questões elaboradas estão diretamente ligadas a área de auditoria de estoques

\section{RESULTADOS E DISCUSSÕES}

Para se entender os resultados alcançados foram elaborado os gráficos contendo os percentuais adquiridos com os questionários alcançados, cujo os mesmo apontaram a opinião 
dos entrevistados e demonstraram de forma o costume da empresa quanto ao uso da auditoria nos estoques.

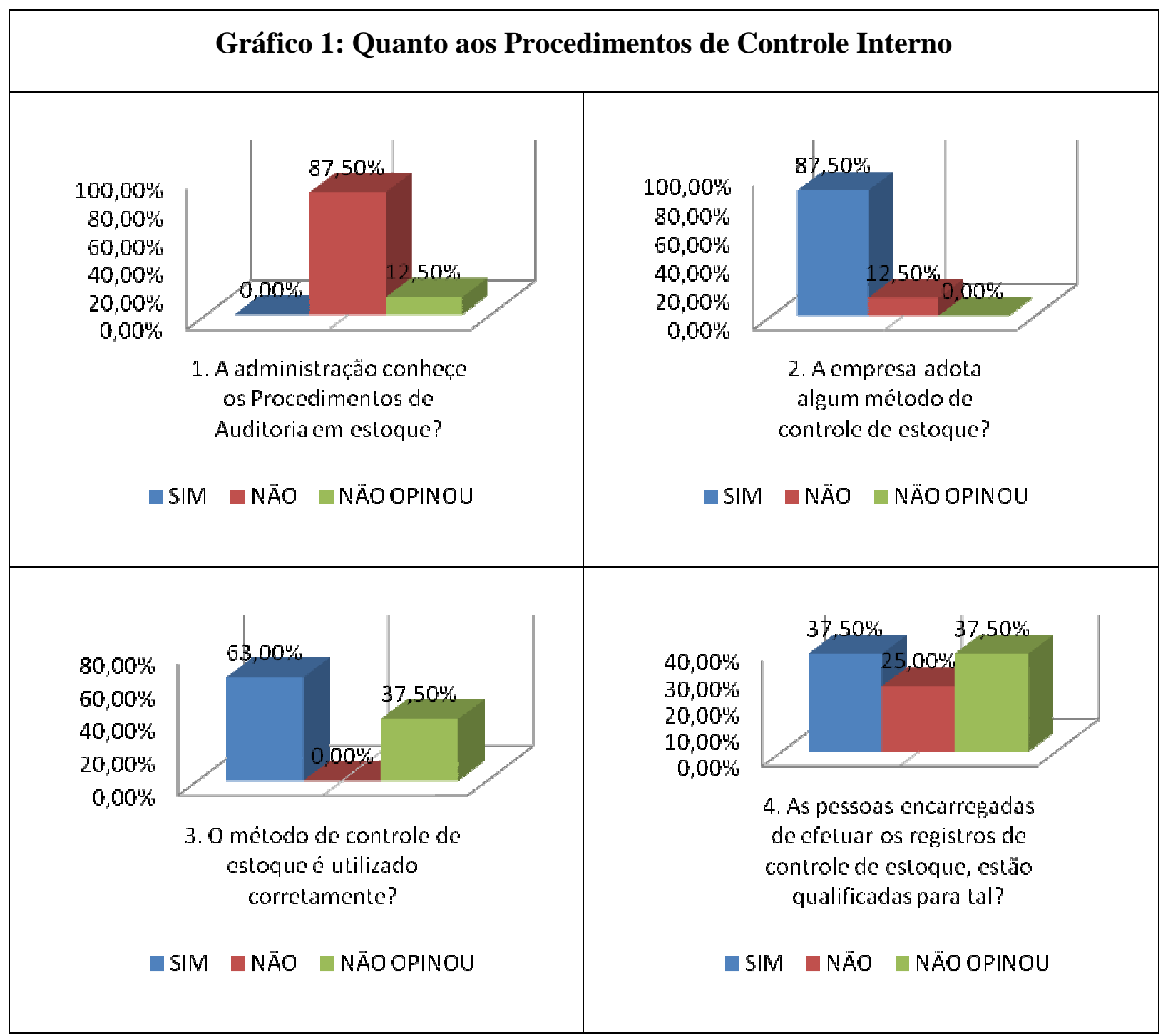

Fonte: Dados da Pesquisa

O gráfico 1 demonstra quais dos procedimentos de controle interno as empresas questionadas utilizam. Quanto a questão 1 apontada acima demonstra que 87,50\% das empresas questionadas não conhecem os procedimentos de auditoria. $\mathrm{O}$ conhecimento desses procedimentos é muito importante, pois consiste em verificar se tudo está sendo feito de acordo com o que foi planejado e as ordens dadas, bem como descobrir as falhas e erros, com o objetivo de repará-los e evitar que possam se repetir na proporção que as atividades vão sendo executadas (SILVA, 1990). Quanto a questão 2 apontada no gráfico 1, demonstra que entre as empresas questionadas $12,50 \%$ não adotam nenhum método de controle de estoque, 
neste ponto torna-se então uma falha para a empresa, pois o controle dos itens de estoque evita o constrangimento das empresas quanto à requisição de um determinado item e este não vir a existir no estoque da empresa. Neste momento destaca-se os procedimentos de auditoria, que busca identificar essas falhas e corrigir determinados erros que venham a ser identificados, é o que afirma Crepaldi (2004). Quanto a questão 3 apontada no gráfico 1 demonstra que $63,00 \%$ dos entrevistados que afirmaram possuir um controle de estoque, fazem uso corretamente e 37,50\% afirmaram ter qualificação para tal, conforme demonstrado na questão 4. Franco (2001), aponta este procedimento como primordial para evitar fraudes dentro das empresas e aconselham também que seja feito a verificação das rotinas e que seja efetuado o controle interno nesta área.

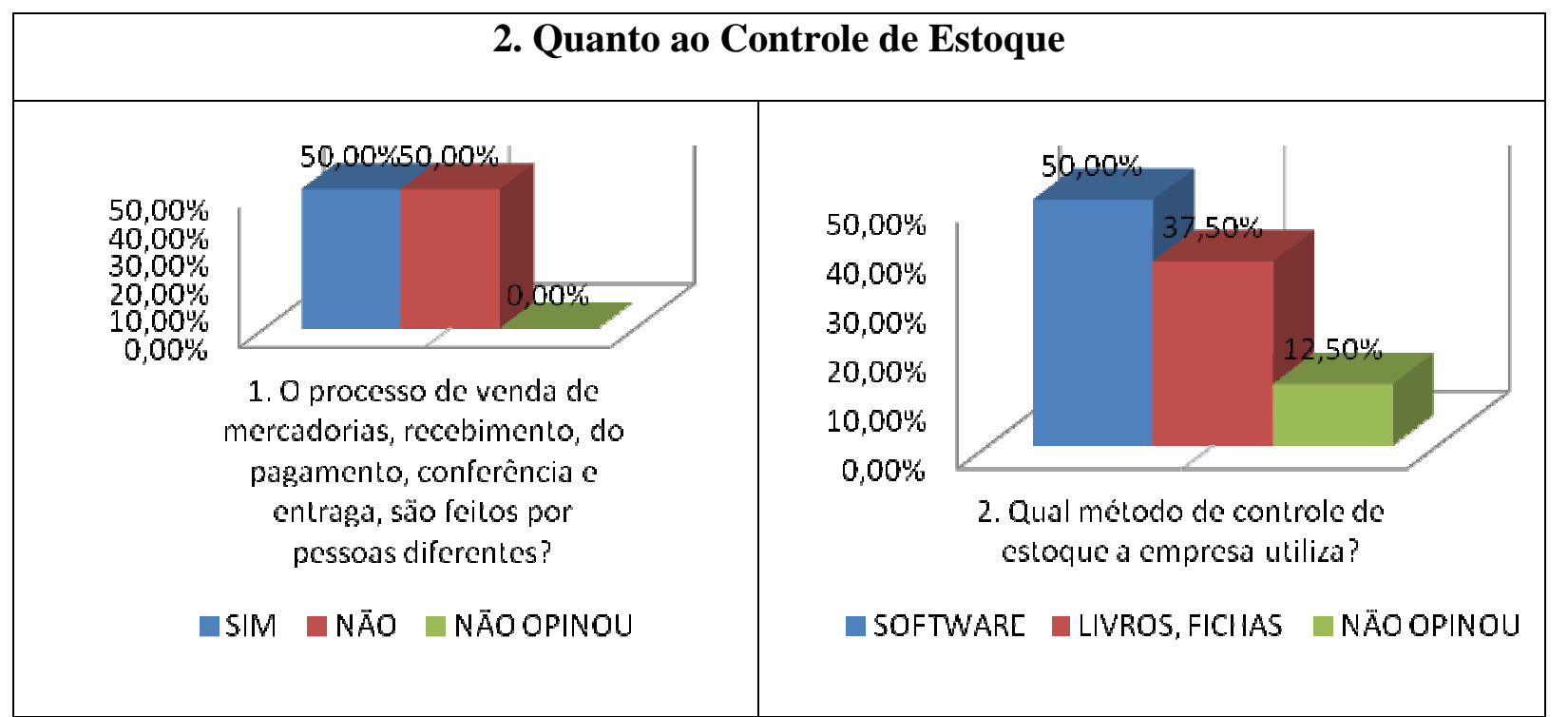

Fonte: Dados da Pesquisa

O gráfico 2 acima demonstra como é feito o controle de estoque das empresas questionadas. Quanto a questão 1, demonstra que 50,00\% das empresas questionadas afirmaram que o processo de venda das mercadorias, recebimento, entrega, são efetuados por pessoas diferentes, este procedimento dificulta o surgimento de fraudes dentro da empresa por empregar várias pessoas no processo. Quanto a questão 2, demonstra entre as empresas questionadas, a utilização de um dos meios de controle de estoque, 50,00\% afirmaram fazer uso de software fornecido por empresas privadas, e 37,50\% afirmaram fazer registro de seus estoque em livros ou fichas.

Os estoques devem impreterivelmente serem resgistrados e controlados de forma que a empresa possa verificar os itens, afim de extinguir as diferenças entre o inventário físico e os registrados em documentos. (FRANCO; MARRA, 2001). Franco (2001) afirma também que os estoques devem ser revistos e deve ser feito planejamento da empresa para efetuar o 
levantamento do inventário físico a fim de assegurar-se quanto à sua adequação, além das reuniões preliminares com os auxiliares e orientá-los devidamente quanto aos pontos mais importantes do controle interno e as peculiaridades de trabalho.

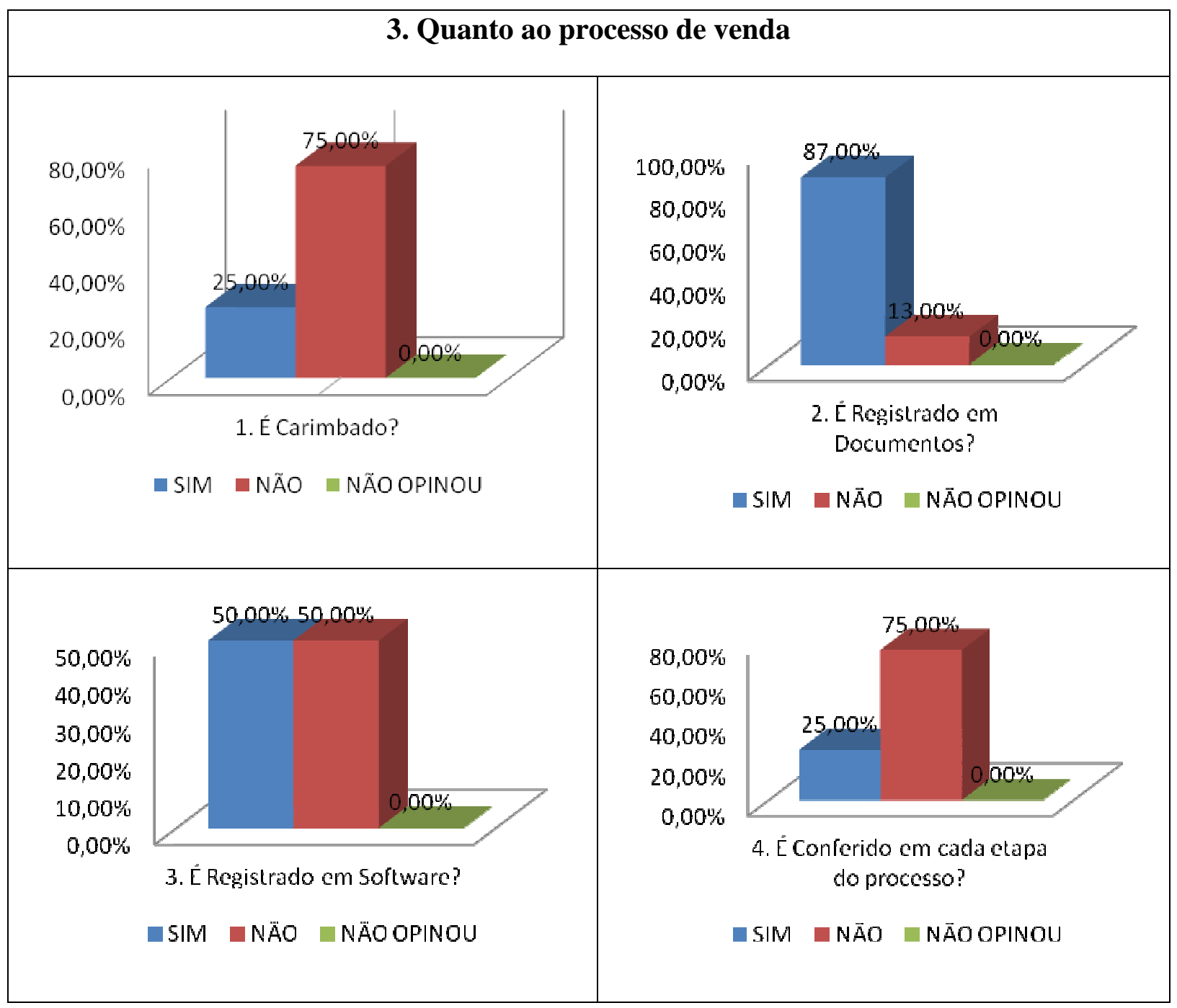

Fonte: Dados da pesquisa

Como os estoques representam o custo das mercadorias possuídas por uma empresa e assumem importância no contexto do Balanço Patrimonial (BP), seus efeitos são imediatamente no Patrimônio Liquido (OLIVEIRA; MARION; 1990, 2003). Dessa Maneira é necessário efetuar o rigoroso controle quanto à saída de mercadorias. O Planejamento torna-se um processo administrativo capaz de determinar antecipadamente as metas que deverão ser atingidas, para produção de relatórios, atendendo plenamente os usuários, sabendo do conhecimento contábil os usuários constroem com enfoque diversos relatórios gerenciais (CREPALDI, 2004). 
Q questão 1 apontada no gráfico 3, demonstra que entre as empresas questionadas $75,00 \%$ afimaram que as sáidas não são carimbadas. A utilização do carimbo nas saídas serve como prova que este percurso foi conferido, a falta do seu uso pode abrir brechas para fraudes e erros. O registro das saídas são tão importantes quanto ao da aquisição, a questão 2, demonstra que $87,00 \%$ das empresas registram suas saídas, esse procedimento de controle é importantíssímo pois serve como registros auxiliares. Os investimentos da empresa destinados à controle, fiscalização e verificação administrativa, possibilitam prever, evitar e dirigir os acontecimentos dentro da empresa e produzem efetos postivos no resultado (FRANCO; MARRA, 2001).

Quanto a quetão 3 do gráfico 3, demonstra que apenas 50,00\% das empresas questionadas fazem controle das saídas em software. Quanto a etapa de conferência essa relatada na questão 4, demonstra que apensas 25,00\% das empresas afirmaram conferir cada etapa do processo, já 75,00\% não fazem esta conferência, o que expõe a empresa a possíveis erros, falhas e fraudes, na maioria das vezes, as fraudes são praticadas por pessoas que possuem autoridade. Quando implicam em números maiores, as fraudes geralmente ocorrem mediante formação de conspiração, sendo assim, mais difícil sua detecção, afirma Sá (2000).

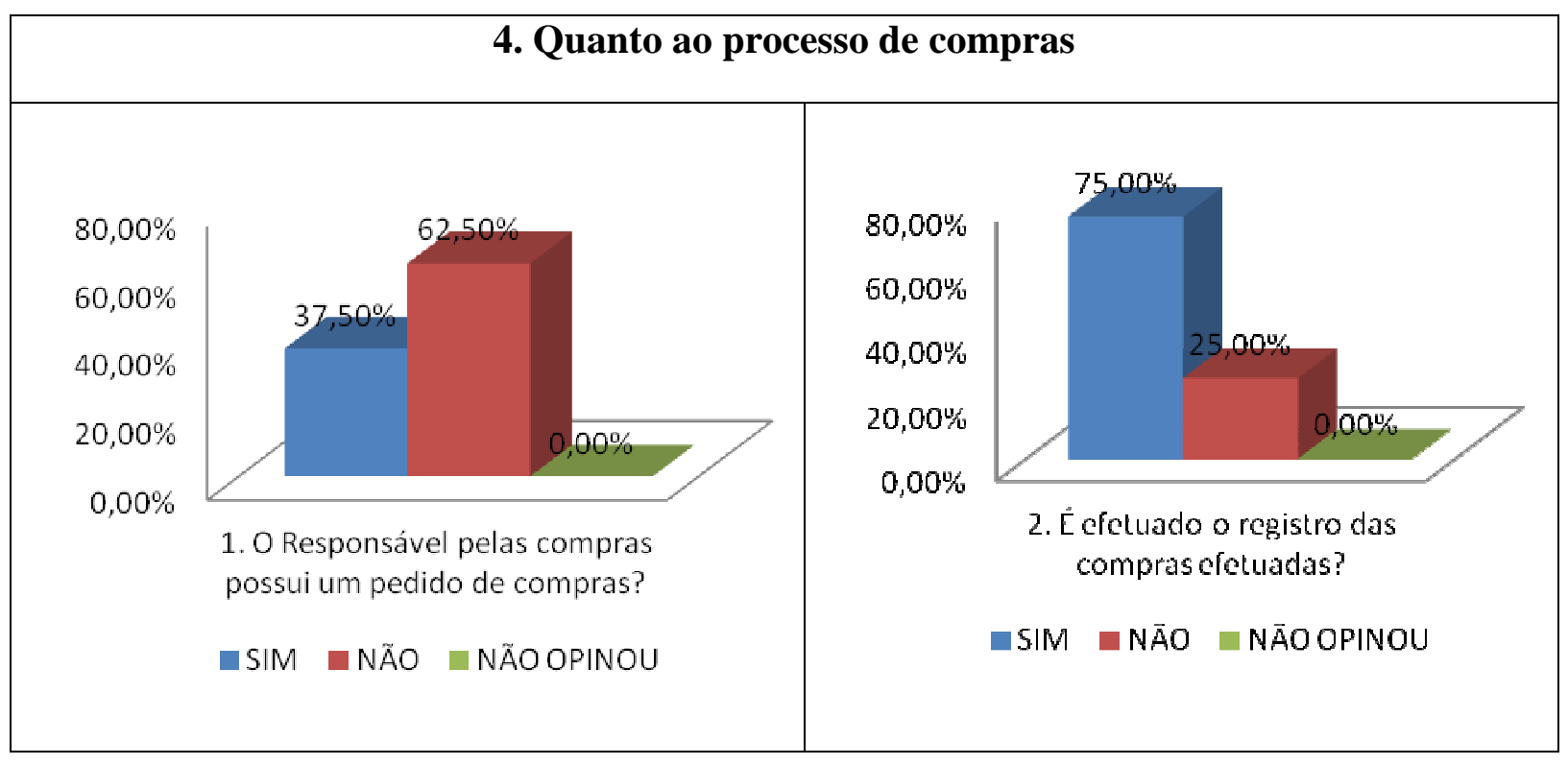




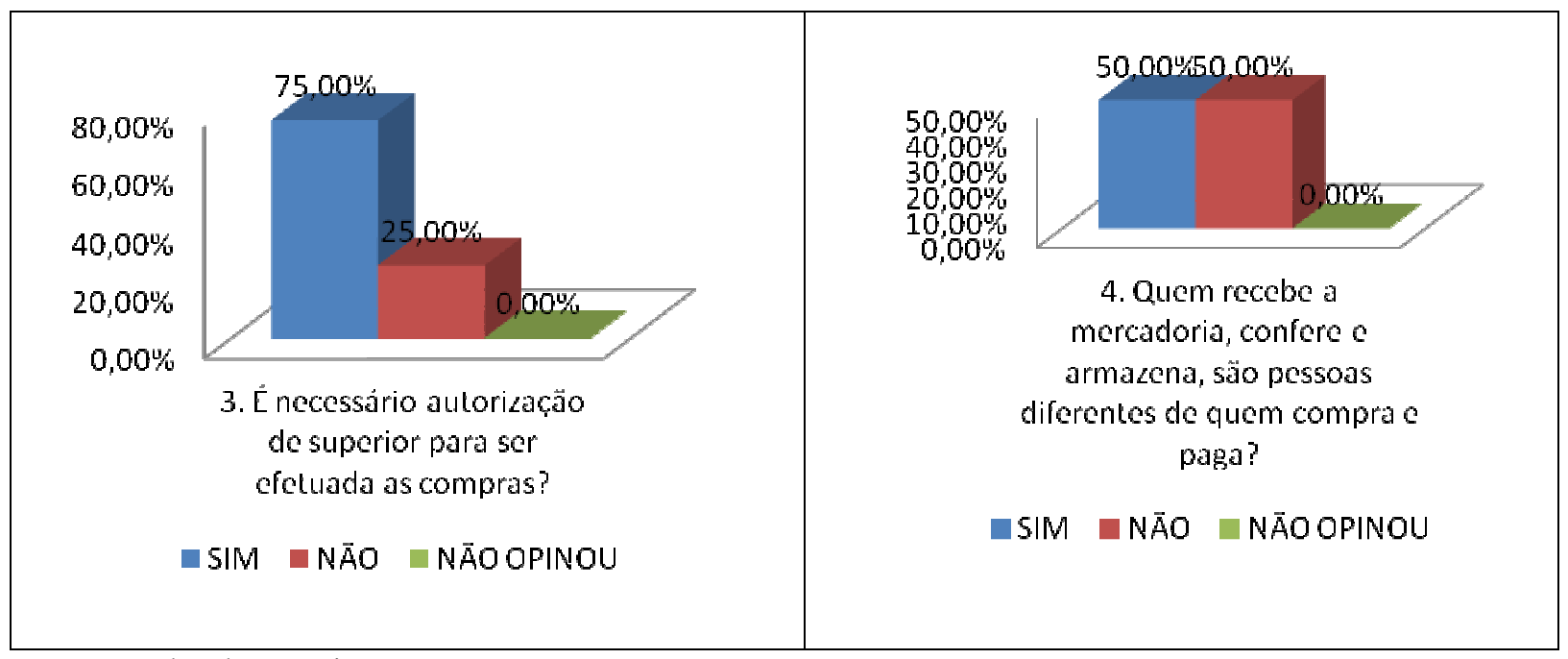

Fonte: Dados da pesquisa

O gráfico 4 acima ilustrado aborda os pricipais procedimentos de controle que devem ser adotados nas empresas quanto a aquisição de mercadorias. A questão 1 aponta que 62,50\% das empresas questionadas afirmaram que o responsável pelas compras não possui um pedido de compra. O pedido de compra nesse processo serve como uma ferramenta de confirmação, afim de evitar que o responsável caia em tentação e cometa fraudes.

Favaro (2001), diz que a tecnologia permite que a empresa acompanhe cada item de seu estoque, mesmo assim ela pode preferir não fazê-lo, por causa dos custos que podem surgir com aquisição do software e dos treinamentos adequados aos funcionários. O importante é que de acordo com os principios contábeis do custo original como base de valor, deve se trabalhar com os valores de aquisição (entradas) das mercadorias, o que pode variar é o critério adotado para sua valoração (FAVARO; STECKNEY, 2001).

Quanto a questão 2 apontada no gráfico 4, demonstra que 75,00\% das empresas questionadas efetuam os registros de compras efetuadas, já 25,00\% não fazem uso deste procedimento. É importante que os valores fisícos de estoques e seus registros no sistema sejam exatos, ou mais parecidos possíveis. A falta de cuidaddo das empresas com a alimentação do sistema acaba gerando uma falta de confiança no usuário que acaba muitas vezes abandonando o uso do sistema. A movimentação de itens do estoque devem ser feito em tempo real para que se matenha exatidão dos registros dos estoques afim de reduzir os custos (CREPALDI, 2004).

$\mathrm{Na}$ questão 3 abordada no gráfico 4, demonstra que 25,00\% das empresas questionadas afirmaram que não é necessário a autorização de um superior para o responsável efetuar as compras de mercadorias, este ponto destaca-se como falha e expõe a emprea a fraudes. Franco (2001) trata esse item como um procedimento primordial para se ter controle 
do que irá compor o estoque. Quanto a questão 4, demonstra que entre as empresas questionadas $50,00 \%$ afirmaram que quem recebe a mercadoria, confere e armazena são pessoas diferentes de quem compra e paga, sendo assim torna-se mais dificil o acontecimento de fraudes neste ponto. O processo de a quisição de materiais influencia a formação de estoque e está relacionada ao equilibrio que existe entre a demanda e o fornecimento. Por ser impossivel prever rigorosamente e demanda dos clientes, faz-se necessário e estoque na empresa, sendo o meio que garante a disponibilidade da mercadoria, sendo assim faz-se a necessidade de efetuar o registro das compras, pois uma das principais funções da administração de materiais relaciona-se com o controle de estoque (BERTAGLIA, 2005; POZO, 2004).

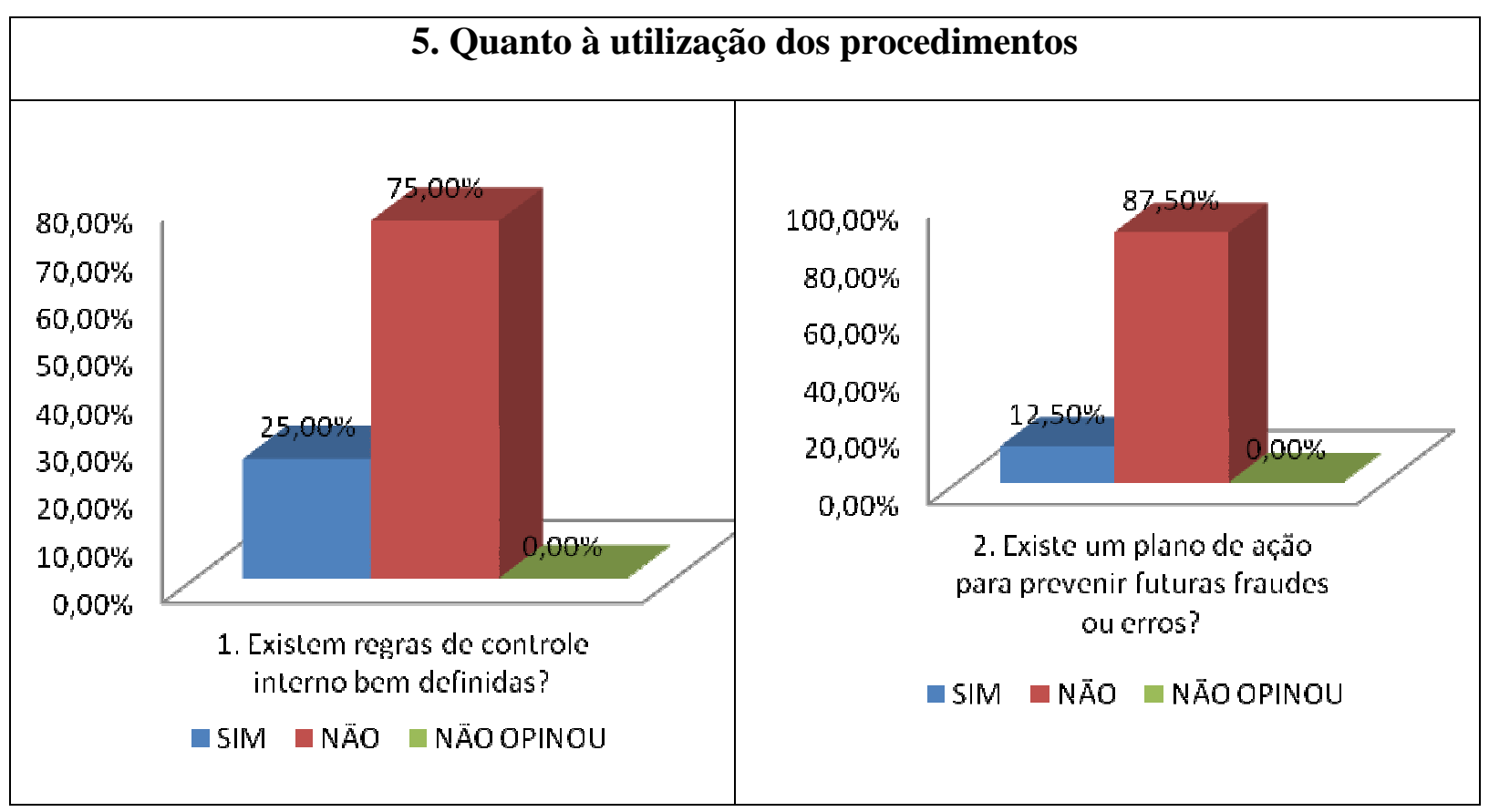




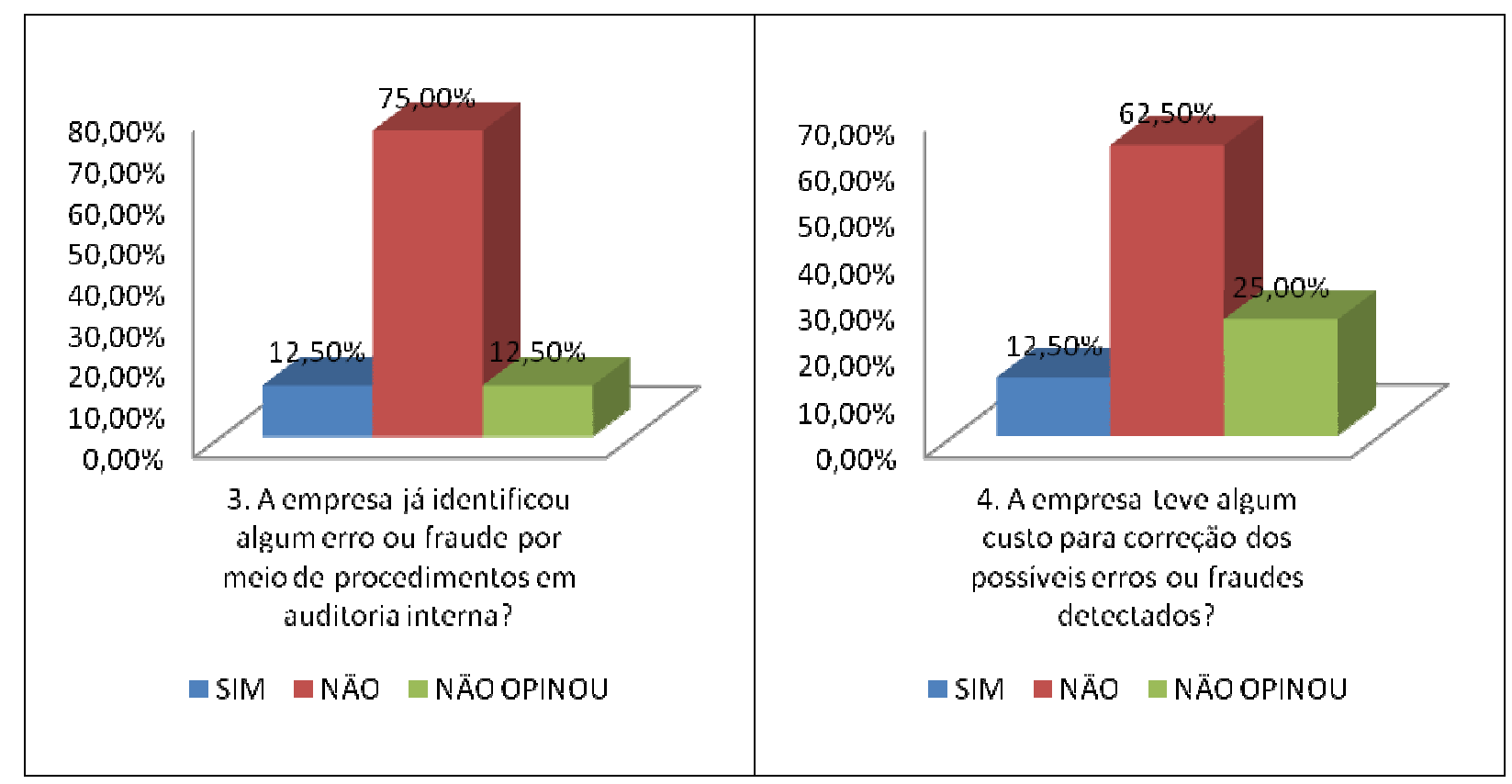

Fonte: Dados da pesquisa

O gráfico 5, apresenta algumas etapas quanto a utilização dos procedimentos de controle interno dentro das empresas questionadas. A questão 1 demonstra que $75,00 \%$ das empresas não possuem regras de controle interno bem definidas, 25,00\% afirmaram que possuem. Essas regras são passadas para os funcionários mediante treinamentos e palestras, a apresentação das regras da empresas para os funcionários é importante para que os mesmos saibam bem como são definidas suas obrigações. Na questão 2 apontada no gráfico 5, demonstra que $87,50 \%$ das empresas questionadas não possuem um plano de execução, que oriente os funcionários quanto a utilização dos procedimentos de controle interno da empresa, que possam prevenir erros e fraudes. Segundo Attie (1998) "o plano de organização é o conjunto corrdenado dos métodos e medidas, adotadas, pelas empresas, para proteger seu patrimônio, verificar a exatidão e a fidedignidade de seus atos contábeis, promeverem a eficiência operacional e encorajar a adesão á politica traçada pela administração.

$\mathrm{Na}$ questão 3 abordada no gráfico 5, demonstra o percentual das empresas questionadas que já encontraram algum erro ou fraude por meio da utilização dos procedimentos de controle interno, no qual 12,50\% afirmaram que encontraram problemas como: mercadoria faltando em estoque, itens registrados com valores incorretos, discrepância entre as quantidades dos itens em estoque e os registrados no sistema entre outos. A questão 4 aponta que dentre os mesmo $12,50 \%$ tiveram algum custo para corrigir os erros encontrados durante o processo, fato que demonstra que a auditoria como ferramenta de prevenção de erros e fraudes se torna relevante tambem na redução de custos operacionais. 


\section{CONSIDERAÇÕES FINAIS}

Foram analisadas empresas do ramo de materiais de construção civil no município de Nova Olímpia, e com base nos dados coletados, foi possível apontar algumas considerações. Inicialmente, observa-se uma característica comum entre os entrevistados, que 87,50\% afirmaram não conhecer os procedimentos de auditoria recomendados, mas consideram-se importante o controle interno, que auxilia na identificação de erros ou fraudes dentro da empresa. Os erros e as fraudes apresentam atualmente um elevado obstáculo para a sobrevivência das empresas no Brasil esta situação não é distinta e ainda são incipientes os dados sobre o tema, (GELATTI; MENEGUETI; 2007). Pode se observar pontos onde existem falhas nas empresas questionadas, isso quando 50,00\% afirmaram que o processo de venda, recebimento, conferência e entrega não são feito por pessoas diferentes, neste ponto pode surgir fraudes, pois quanto mais usuários envolvidos no processo, ou seja maior dificuldade de ocorrência de fraudes. De parte das empresas que fazem controle de seus estoques, 50\% fazem o uso de software para controlar seu estoque e efetuar seus registros. A utilização das ferramentas de controle interno diminui os fatos que possibilitam as ocorrências de erros e fraudes internamente, algo que possa afetar a saúde financeira da empresa.

O objetivo apresentado nesta pesquisa foi alcançado, visto esse que dentro as empresas questionadas, $87,00 \%$, afirmaram não conhecer os procedimentos de auditoria. Quanto aos objetivos específicos foram alcançados, pois pode se observar em alguns pontos falhas no controle de estoque das empresas questionadas, como na questão 3 do gráfico, onde $25,00 \%$ das empresas afirmaram que não é necessário autorização de um superior para o responsável efetuar as compras.

Durante a realização deste artigo foram impostos algumas limitações em sua elaboração, como a falta de colaboração de alguns empresários, que não se propuseram a responder os questionários. Este mesmo artigo poderá servir de linha de pesquisa para outros acadêmicos que se interessem em efetuar o mesmo levantamento em outras regiões, outras áreas enfim. Foram apresentado os resultados às empresas questionadas, as mesmas analisaram os dados levantados e perceberam onde seu controle de estoque é mais frágil e sucessível a erros. Quanto aos procedimentos que os empresários desconheciam, os mesmo se propuseram a tentar implantar na empresa e fazer uso freqüente desse procedimentos eficazes, demonstrando a importância que a universidade tem para com a sociedade, promovendo o conhecimento aos seus acadêmicos, formando profissionais competentes e conscientes de seu papel de cidadão. 


\section{REFERENCIAS BIBLIOGRÁFICAS}

ALMEIDA, Marcelo C. Auditoria: um curso moderno e completo. São Paulo: Atlas, 2003.

ATTIE, William. Auditoria, conceitos e aplicações. 3 edição. São Paulo: Ed. Atlas, 1998.

BERTAGLIA, Paulo R. Logística e gerenciamento da cadeia de abastecimento. 1 ed. São Paulo: Saraiva, 2005.

BEUREN, Ilse M. Como Elaborar Trabalhos Monográficos em Contabilidade: teoria e prática. 3. Ed. São Paulo: Atlas, 2006.

CORREA, Henrique. L. Planejamento Programação e controle da produção, conceitos, uso e implantação, São Paulo: Atlas, 2000.

CONSELHO FEDERAL DE CONTABILIDADE. CFC No986/03, disponível em <http://www.cosif.com.br> acesso em 01 de agosto de 2011.

CREPALDI, Silvio A. Auditoria contábil: teoria e prática. 3 ed. São Paulo: Atlas, 2004.

DIAS, Marco A. P. Gerência de materiais. São Paulo: Atlas, 1986.

FAVARO, H.L; LEONARDONNI, C.S; et al. Contabilidade: Teoria e Pratica. In: Operações com Mercadorias; Critérios de Avaliação de Estoques. 2. ed. São Paulo: Atlas, 1997.

FRANCO, Glenda. Vale, Laila; A importância e influencia do setor de compras nas organizações. Revista Techoje. Disponível em: 〈http://www.ietec.com.br> acesso em 15 de setembro de 2011.

FRANCO, Hilário.; MARRA, Ernesto. Auditoria Contábil: Normas de auditoria, procedimentos e papeis de trabalho, programas de auditoria, relatórios de auditoria. São Paulo: Atlas, 2001.

GIL, Antonio de L. Sistemas de informações contábil / financeiro. 1 ed. São Paulo: Atlas, 1992. 
GELATTI, Cristiane B. MENEGHUETTI, Daniela.: FREITAS, Renata Oliveira.: TRINDADE, Larissa de Lima: A Importância da auditoria nos estoques, UFSM 2007. Disponível em: <_w3.ufsm.br/revistacontabeis> acesso em 31 de Julho de 2011.

IUDÍCIBUS, Sergio de. MARION, José C. Contabilidade comercial. 2 ed. São Paulo: Atlas, 1986.

JUNIOR, Sergio L. S. Noções básicas de almoxarifado, estoque, transporte de materiais. 1 ed. São Paulo: Revista Artigonal, Abril 2009.

LAUGENI, Fernando P. ; MARTINS, Petrônio G. Administração da produção. São Paulo: Saraiva, 2002.

LAKATUS, E. M.; MARCONI, M. A. Técnicas de pesquisa: planejamento e execução de pesquisas, elaboração, análise e interpretação dos dados. 4. ed. São Paulo: Atlas, 1985.

LÍRIO, José E. P. A auditoria de estoques como proposta para redução de perdas e mensuração de resultados. Disponível em <http://www.administradores.com.br > acesso em 02 de Agosto de 2011.

MARION, José C. Contabilidade empresarial. 10 ed. São Paulo: Atlas, 2003.

NORMAS BRASILEIRA DE CONTABILIDADE, CFC 1.170/2009, disponível em <www.cosif.com.br> acesso em 5 de Agosto de 2011.

Normas Brasileiras de Contabilidade. NBC T11: Auditoria independente das demonstrações contábeis.

OLIVEIRA, Djalma de P. R. Sistemas, organização e métodos: uma abordagem gerencial. 4 ed. São Paulo: Atlas, 1990.

OLIVEIRA, Álvaro G.de.Contabilidade financeira para executivos. in: correção monetária dos recursos aplicados em ativos não-monetários; estoques. 5. ed. Rio de Janeiro: Fundação Getúlio Vargas, 1999.

PADOVEZE, Clovis L. Contabilidade Gerencial: Um enfoque em sistema de informação contábil. 4 ed. São Paulo: Atlas, 2006. 
POZO, Hamilton, Administração de recursos materiais e patrimoniais: uma abordagem logística. 3 ed. São Paulo: Atlas, 2004.

RIBEIRO, Magno A. TORRES, Ariel L. ROCHA. Margarida A. Manual para elaboração e apresentação de monografias: com noções introdutórias de metodologia. 1 ed. Tangará da Serra: Sanches, 2006.

SÁ, Antonio L. Curso de auditoria. 9. ed. São Paulo: Atlas, 2000.

SANTI, Paulo A. Introdução à auditoria. São Paulo: Atlas, 1998.

SILVA, Adelphino T. Organização e técnica comercial. 16 ed, São Paulo: Atlas, 1990.

STECKNEY; Weil. Contabilidade financeira: uma introdução aos conceitos métodos e usos; ed. São Paulo: Atlas, 2001. 